$\stackrel{W}{=}$

Global burnals Inc.

है

\title{
Results of Salt Cognition Test using SALSAVE since 67 Female University Students
}

By Naomi Katayama, Akemi Ito \& Mayumi Hirabayashi

Nagoya Women's University

Abstract- In Japan, salt reduction is encouraged to prevent high blood pressure. However, it is difficult to reduce salt, and good salt intake per day did not fail to the target value. In this study, we report a saltiness cognitive threshold test using female university students. The participant is 67 female university students. Participants were subjected to a salty cognitive threshold test using SALSAVE (manufactured by Advantech). The saltiness test started from a light taste and tried a strong taste in order. The salt concentration is $0.6 \%, 0.8 \%, 1.0 \%, 1.2 \%, 1.4 \%, 1.6 \%$. We also conducted a questionnaire survey on eating habits. As a result, 62 out of 67 female university students who felt salty at a concentration of $0.6 \%$ were92\% of all participants. However, two female university students did not feel taste even with a salt concentration of $1.6 \%$. They are $3 \%$ of all participants. As a result of the questionnaire survey, female university students answered that they had a good taste and secreted saliva well, and they usually had a rather light diet. In the future, we would like to increase the number of participants and compare more detailed dietary habits with SALSAVE results.

Keywords: saltiness test, cognition, threshold, salsave, university student.

\section{GJMR-K Classification: NLMC Code: QU 84}

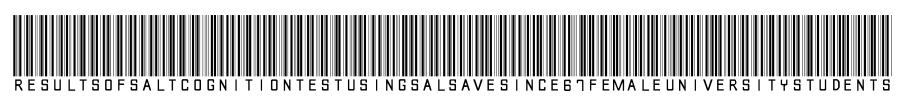

Strictly as per the compliance and regulations of:

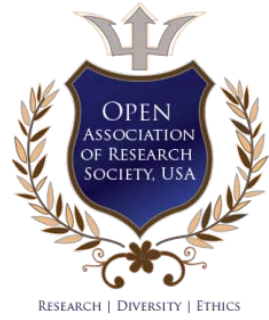

(C) 2020. Naomi Katayama, Akemi Ito \& Mayumi Hirabayashi. This is a research/review paper, distributed under the terms of the Creative Commons Attribution-Noncommercial 3.0 Unported License http://creativecommons.org/licenses/by-nc/3.0/), permitting all non-commercial use, distribution, and reproduction in any medium, provided the original work is properly cited. 


\title{
Results of Salt Cognition Test using SALSAVE since 67 Female University Students
}

\author{
Naomi Katayama ${ }^{\alpha}$, Akemi Ito ${ }^{\circ} \&$ Mayumi Hirabayashi ${ }^{\circ}$
}

Abstract- In Japan, salt reduction is encouraged to prevent high blood pressure. However, it is difficult to reduce salt, and good salt intake per day did not fail to the target value. In this study, we report a saltiness cognitive threshold test using female university students. The participant is 67 female university students. Participants were subjected to a salty cognitive threshold test using SALSAVE (manufactured by Advantech). The saltiness test started from a light taste and tried a strong taste in order. The salt concentration is $0.6 \%$, $0.8 \%, 1.0 \%, 1.2 \%, 1.4 \%, 1.6 \%$. We also conducted a questionnaire survey on eating habits. As a result, 62 out of 67 female university students who felt salty at a concentration of $0.6 \%$ were92\% of all participants. However, two female university students did not feel taste even with a salt concentration of $1.6 \%$.They are $3 \%$ of all participants. As a result of the questionnaire survey, female university students answered that they had a good taste and secreted saliva well, and they usually had a rather light diet. In the future, we would like to increase the number of participants and compare more detailed dietary habits with SALSAVE results.

Keywords: saltiness test, cognition, threshold, salsave, university student.

\section{InTRODUCTION}

apanese Dietary Intake Standards in the 2020 version, the daily intake of salt for females in recommended to be $6.5 \mathrm{~g}$ or less. Salt intake is decreasing with each revision of dietary standards. In the near future, it is expected that salt intake in Japannese dietary intake standards will lower to the international standard of $6.0 \mathrm{~g}$. By reducing salt, it expected to prevent illness from various diseases (high blood pressure, kidney disease, heart disease, etc.). Therefore, the purpose of this study was to conduct a salt concentration cognition test on Japanese people to understand the actual condition of the cognitive threshold for salt, and to use it as future data. To begin with, we report that a healthy female university student underwent a salt concentration recognition test.

\section{il. Materials and Methods}

\section{a) Participants}

The participant is 67 female university students. Their average age \pm standard deviation(SD) was $29.6 \pm 0.6$, average height \pm SD was $158.9 \pm 5.7 \mathrm{~cm}$, and average weight $\pm \mathrm{SD}$ was $50.3 \pm 4.5 \mathrm{~kg}$ (Table 1).

Table 1: Average \pm Standard diviation (SD) of participant's age and body composition $(n=67)$

\begin{tabular}{cccc}
\hline \hline Participants & Age & Height & Weight \\
\hline Average & 20.6 & 158.9 & 50.3 \\
S D & 0.6 & 5.7 & 4.5 \\
\hline \hline
\end{tabular}

b) Assessment of salt taste identification

Participants were subjected to a salty cognitive threshold test using SOLSAVE (manufactured by Advantech). The saltiness test started from a light taste and tried a strong taste in order. The saltiness test starts form $0.6 \%$, and the concentration increases by $0.2 \%$ in 6 steps up to $1.6 \%$. Participants put a filter paper impregnated with salt in their mouth to check the taste, and then answered to the inspector what the teste was. The inspector recorded the answers of the participants.

We also conducted a questionnaire survey on dietary habits. There are four questions, 1) Does saliva come our? 2) Do you feel the taste? 3) Frequency of purchase of restaurants and commercial food, 4) Regular seasoning (for food was salty or thin) (Table 2).

Author a $\sigma \rho$ : Graduate School of Nagoya Women's University, Nagoya City, Japan.

Corresponding Author a: Nagoya Women's University, Nagoya City, Japan.e-mail: naomik@nagoya-wu.ac.jp 
Table 2: Questionnaire survey items

\begin{tabular}{|c|c|c|c|c|}
\hline & Question 1 & Question 2 & Question 3 & Question 4 \\
\hline & Saliva secretion & Taste perception & Use of restaurants and commercial food & Favorite food salt taste \\
\hline 1 & Very well & Very well & every day & Strong salt taste \\
\hline 2 & Well & Well & four or five times a week & rather strong salt teste \\
\hline 3 & Not good & Not good & two or three times a week & rather light salt teste \\
\hline 4 & Do not know & & once a week & light salt taste \\
\hline 5 & & & two or three times a month & \\
\hline 6 & & & Hardly used & \\
\hline
\end{tabular}

c) Ethical review board

This study conducted with the approval of the Ethics Committee (Nagoya women's university 'hitowo mochiita kennkyuuni kansuru iinnkai'). The approval number is $30-14$

\section{Results}

a) Saltiness recognition test result

Sixty-seven female university students underwent a saltiness cognitive threshold test using

Table 3: Female University students Saltiness cognitive threshold test results $(n=67)$
SALSAVE. As a result, 62 out of 67 female university students who felt salty at a concentration of $0.6 \%$ were $92 \%$ of all participants. And, three female university students felt a salt concentration of $0.8 \%$, were $4.5 \%$ of all participants. However, two female university students did not feel taste even with a salt concentration of $1.6 \%$. This is $3 \%$ of all participants (Table3).

\begin{tabular}{lccccccc}
\hline \hline & $0.60 \%$ & $0.80 \%$ & $1.00 \%$ & $1.20 \%$ & $1.40 \%$ & $1.60 \%$ & $1.6 \%$ 以上 \\
\hline Participants (number of students) & 62 & 3 & 0 & 0 & 0 & 0 & 2 \\
Participants (\%) & 92.5 & 4.5 & 0.0 & 0.0 & 0.0 & 0.0 & 3.0 \\
\hline \hline
\end{tabular}

b) Questionnaire results

Table 4 shows the results of the questionnaire survey. When asked if they had enough saliva, most female university students replied that they had enough or normal secretions. None of the female university students answered that they had none or poorsaliva. In response to the question of feeling the taste, most female university students answered that they could well or understand the taste. None of the female university students answered that they didn't understand the question of whether they would feel the teste. When asked about the frequency of use of restaurants and groceries, female university students answered that they would use 2-3 times a week or once a week. When asked if the usual seasoning for food was salty or not too much salty, female university students answered that they were the lightly salted.

Table 4: Results of Questionnaire survey conducted on female university students $(n=67)$

\begin{tabular}{lcccc}
\hline & Saliva secretion & Taste perception & Use of restaurants and commercial food & Favorite food salt taste \\
\hline Average & 1.3 & 1.5 & 3.8 & 2.3 \\
S D & 0.7 & 0.5 & 1.0 & 0.7 \\
\hline
\end{tabular}

\section{Discussion}

Many researchers have reported the relationship between salt intake and blood pressure ${ }^{1)}$ and the relationship between hypertension $2,3,4)$. There are also reports on diet and salt intake in the younger generation ${ }^{5)}$. We also reported the results of the saltiness cognition threshold test conducted by Yakumo Study on the elderly ${ }^{6,7)}$. There are also reports on the relationship between salt intake and blood pressure overseas ${ }^{8,9)}$, as well as educational effects on salt intekae ${ }^{10,11)}$. Currently, many new drugs for lowering blood pressure have developed for people with high blood pressure ${ }^{12)}$, but dietary food habits also desirable can be improved their blood pressure. The drug also has side effects and that costs a lot to keep taking it. In Alzheimer's dementia, the taste is not known, and the value of the salty cognitive threshold teat also deteriorates ${ }^{13)}$. Therefore, it is highly likely that the dietary intake will be high, which may raise blood pressure. A low saltiness recognition threshold means that the saltiness of the meal can reduced. Keeping the salty cognitive threshold low makes sense for a healthy diet. We conducted a saltiness cognition threshold test on 67 young female university students. As a result, they recognized $0.6 \%$ saltiness, and with included $0.8 \%$ recognized students, the total number of recognized was $96.5 \%$. The result of the dietary habit questionnaire showed that saliva was well secreted, the taste of the meal was well understood, and the dietary intake was 
light. However, two female university students did not feel taste even with a salt concentration of $1.6 \%$. This is $3 \%$ of all participants.

In the future, we would like to conduct a more detailed questionnaire survey on dietary intake and compare it with the salty cognitive threshold test results.

\section{Conclusions}

The results of this test show that most female university students (92\%) feel salty at $0.6 \%$. Also, female university students were eating a light taste in their daily life. Moreover, the use of restaurants and the use of commercially available foods were once or 2-3 times a week. The effect of the salt reduction awareness campaign in Japan, which has continued for over 20 years, is good for the younger generation. However, on the other hand, among the female university students who participated in this study, two students could not recognize $1.6 \%$ saltiness, so it is necessary to investigate the dietary habits of the participants is more detail.

\section{ACKNOWLEDGEMENTS}

This study was supported by the research aid of Choju-iryo-kenkyu-kaihatsuhi 30-14 and the Japanese Society of Taste Technology, 2019.

\section{References Références Referencias}

1. Volos BE, Vasil'ev lu M, Masliaeva LV and Snegurskaia IA (1994). Taste receptor response to sodium chloride and naturiuresis in the workers and employees of an industrial enterprise. Likars'ka sprava 3-4.

2. Olayemi SO and Mabadeja AF (2003). Comparative study of salt taste threshold of jypertensives, their normotensive relatives and non-relatives. The Nigerian postgraduate medical journal 10 (2).

3. Elias SO, Azinge EC, Umoren GA, Jaja ST and Sofola OA (2011). Salt-sensitivity in normotensive and hypertensive Nigerians. Nigerian quarterly journal of hospital medicine 21 (1).

4. Volkov VS, Poseliugina OB, Nilova SA, Vinogradova TS, Rokkina SA and Svistunov OP (2010). Impsired gustatory sensitivity of the tongue to table salt as a risk factor of arterial hypertension. Klinicheskaia meditsina 88(1).

5. Malaga S, Diaz JJ, Arguelles J, Perillan C, Malaga I and Vijande M (2003). Pediatric nephrology 18(5).

6. Katayama N, Kondo S, Ootake H et al (2018). Odour and Salt Taste Identification in Older Adults: Evidence from the Yakumo Study in August, 2018. Acade. J. Med. Plants 7(3) 066-071.

7. Nishimoto K, Ohhori J, Shimomugi T, Kurono Y (2005). Reproducibility of taste examination with Salsave: Control study for healthy volunteers. Japan Society of Stomato-pharyngology. pp.309-315.
8. Cho H, Kinm SM, Jeong SS and Kim SB (2016). Comparison of salt taste thresholds and salt usage behaviours between asults in Myanmmar and Korea. Asia Pacific journal of clinical nutrition 25 (4).

9. Okoro EO, Uroghide GE and Jolayemi ET (1998). Salt taste sensitivity and blood pressure in adolescent school children in southern Nigeria. East African medical journal 75 (4).

10. Kusabe U, Mori $Y$, Okagaki M, Neriya $H$, Adachi $T$, Sugishita C, Aonomura K, Kimura T, Kishimoto N, Nakagawa $\mathrm{H}$, Okigaki M, Hatta $\mathrm{T}$ and Matsubara $\mathrm{H}$ (2009). Sodium restriction improves the gustatory threshold for salty taste in patients with choric kidney sisease. Kidney international 76 (6).

11. Ferrante D, Apro N, Ferreira $\mathrm{V}$, Virgolini M, Aguilar V, Sosa M, Perel P and Casas J (2011). Feasibility of salt reduction in prcessed foods in Argentina. Pan American journal of public health 29 (2).

12. Petrova TS, Bazhenov ND, Mazur VV and Mazur ES (2012). Gustatory sensitivity threshold to table salt and efficacy of the treatment of newly diagnosed patients with antihypertensive therapy. Klinicheskaia meditsina 90 (4).

13. Contri-Degiovanni PV, Degiovanni GC, Ferriolli E, Da Costa LNK and Moriguti JC (2020). Aging clinical and experimental research 2 . 